\title{
Música da Borda d'Água - nos textos e imagens de Alves Redol ${ }^{1}$
}

DOMINGOS MORAIS

“ Há que restituir ao povo a sua música. Há que restituir-lha por dever e por necessidade: por dever humano e por necessidade estética.”

(Fernando Lopes-Graça, 1941)

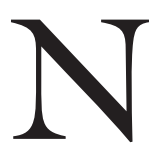

A NOITE de 25 de outubro de 1940, Alves Redol esteve no Sport Lisboa e Vila Franca, no I Serão de Arte. Nessa sessão, em que participou

Arquimedes da Silva Santos, foram lidos poemas de Mário Dionísio, Álvaro Feijó, Manuel da Fonseca e Joaquim Namorado. A encerrar, uma palestra de Alves Redol sobre a "Música da Borda d’Água”, com a colaboração de Carlos Tomé e Sebastião Góis.

O cartaz original onde se lê esta notícia vem reproduzido no catálogo (Santos, 2011, p.119) da exposição comemorativa do centenário de Alves Redol (Figura 1).

Dessa palestra não há registo conhecido. Faremos por isso referência a textos de Redol, alguns inéditos, que nos foi possível consultar e digitalizar nos acervos de António Mota Redol, em outubro de 2012, dos anos de 1938 e 1939 (Figura 2):

- O Fandango (Alves Redol, 1939a). Palestra proferida no primeiro serão de arte, organizado pela secção cultural do Sport Lisboa e Vila Franca, na noite de 18 de Janeiro de 1939.

- Música Popular (Alves Redol, 1939b). Palestra proferida no segundo serão de arte, organizado pela secção cultural do Sport lisboa e Vila franca, na Sociedade União Musical, na noite de 29 de março de 1939.

- A Arte do Povo do Ribatejo (Alves Redol, 1938 [1939c]), (Introdução, Arte Manual, Cancioneiro, Música, Baile). Conferência realizada a 10/7/1938 no Cinema - Teatro de Vila Franca de Xira (Figura 3).

Na palestra sobre Música Popular (Redol, 1939b), em que participaram alguns músicos e grupos musicais, realizada a 29 de março de 1939, Redol diz-nos o que entende por música popular:

Simples e cândida, bela e emotiva, ouvimos nos seus instrumentos e na sua voz a música do povo. Logo, [em chusma], vieram os imitadores com produções falsas de simplicidade e candura, falsas de beleza e emoção, fazer música a que chamam popular $[\ldots]$. 
[...] E nasceu a escola de revista, a escola que se pode designar de escola do Parque Mayer tão relacionada está essa música com o ambiente desse chamado parque de diversões, colmeia de quantas vítimas, desta sociedade torpe, ali oferecem sorrisos e carícias. A música de revista é, na sua generalidade, reles e fútil como a revista em si $[\ldots]$.

[...] E chamamos-lhe música porque ainda não houve um filólogo, um mestre da língua, que se desse ao trabalho de criar um novo vocábulo para distinguir a música de um Wagner ou de um Stravinsky da chamada música de um revisteiro qualquer $[\ldots]$.

[...] A música é forma mais elevada de expressão artística que o homem conhece. É um conjunto de sons dispostos entre si, de maneira a criar um estado de espírito superior que tanto pode levar uma multidão a estagnar-se em êxtase como a lançar-se ao fragor de uma batalha onde a morte a espera [...].

[...] A música é um apelo aos sentidos, é uma arte que socializa emoções [...].

[...] Ora a música a que chamam popular nada disso contém [...].

[...] Música popular é aquela que o povo cria ou a que o povo assimila e guarda e modifica à sua maneira dando-lhe nova beleza $[\ldots]$.

[...] Cada homem trás dentro de si o gérmen de todo o mal e de todo o bem. E o povo ao ouvir a música de revista, pode acarinhá-la, assimilando-a aos seus sentimentos mesquinhos. Pode cantá-la e assobiá-la, mas vem a esquecê-la. É que o povo, por uma intuição superior, pelo maior grau dos seus sentimentos elevados, só assimila e guarda e modifica à sua maneira, dando-lhe nova beleza, o que é simples, fluente e emotivo [...].

[...] Deste modo, entendo necessário que se devem criar divisões estanques onde se encerre o que de facto é popular, o que se dirige ao povo com elevação e o que pretende agradar-lhe chamando os seus sentimentos inferiores [...].

[...] Chamaremos, portanto, popular, ao que o povo cria ou assimila, adaptando $[\ldots]$.

[...] São produções simples, de uma emoção chã, encantadora e expressiva. Vemos estas características no fandango, nos verde-gaios, na caninha verde, etc. $[\ldots]$.

[...] Chamaremos música populista aquela que busca no povo os seus temas, ofertando-lhe elevação, novos ritmos, nova beleza, e que se lhe dirige de novo, voltando ao ponto de partida, num objectivo de educação artística. Encontramos essa justificação nas páginas de um Glinka, de um Cui, ${ }^{2}$ de um Granados, de um Rey Colaço [...].

[...] À música falsamente popular e a que não pode caber a primeira designação, por lhe faltar graciosidade e muito menos à segunda, por não conter uma centelha de elevação, chamaremos música populeira. E se aqui deveremos classificar certas modinhas, determinadas marchas, certos fados, não nos esqueçamos de incluir as músicas e os versos de muitos ranchos que por aí se exibem, em manifestações chamadas de folclore [...].

[...] Só é folclórico o que é tradicional, tanto em indumentária, como em cancioneiro, como em música, como em dança [...].

[...] Ora na sua maioria esses ranchos nada nos mostram do património espiritual das suas regiões. Pretendem antes aproximarem-se dos corpos de baile das revistas $[\ldots]$. 


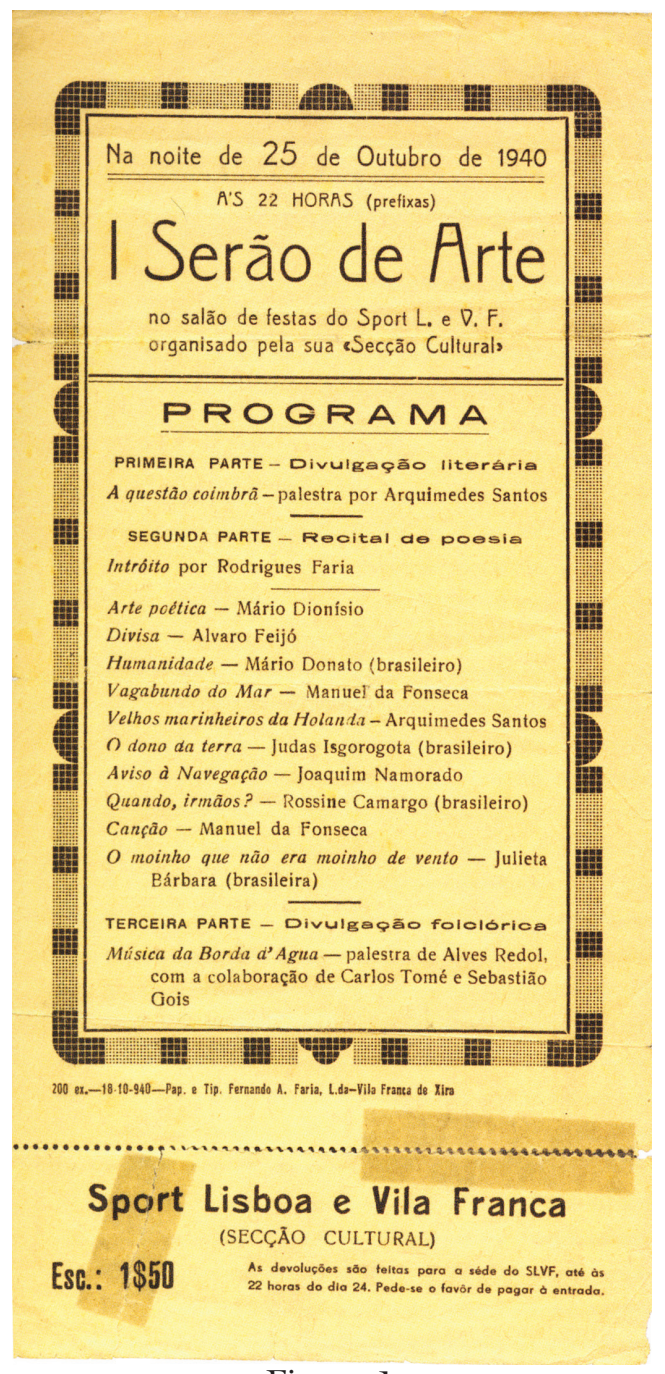

Figura 1

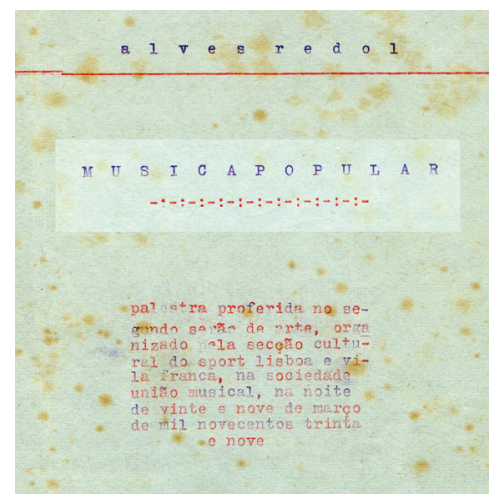

Figura 2

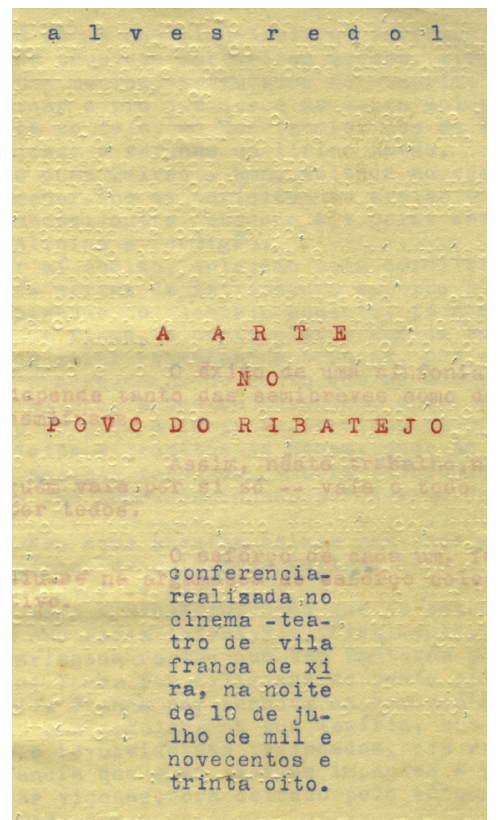

Figura 3

[...] Definida assim o que é musica popular, populista e populeira, digamos alguma coisa sobre as origens da música e do caso português, em especial, pois é de música popular portuguesa que me propus alinhavar estas considerações [...].

Fala de seguida da presença da música nas comunidades humanas de todos os tempos e de como em Portugal a construção de uma identidade decorre de múltiplas influências e em que as formas musicais, os instrumentos e contextos de utilização se adaptam à mudança social e respondem às necessidades de cada momento histórico. As referências aos Cancioneiros medievais, a Afonso X e às cantigas de Santa Maria, a Martin Codax, às cantigas de amigo de D. Diniz, dos trovadores e jograis, das influências recíprocas do popular e do erudito, nas canções e danças em que cita Gil Vicente e fala com conhecimento de causa de danças como a chacota, a folia e os bailes (ballus) de terreiro mostram como o seu interesse pela música fazia parte do que considerava necessário para o seu trabalho. 
A referência à época das Navegações, que trás a Portugal "as mais diversas gentes do globo" e os caminhos da "música culta" que ganhava autonomia e se distinguia da popular e das suas práticas - as procissões e bailes nos terreiros, para cantar e bailar. "Só os cegos de terra em terra, dedilhando os seus instrumentos e cantando, lembravam por vezes, a época exuberante dos trovadores e jograis" (Redol, 1939b).

Redol faz depois profissão de fé no trabalho como desencadeador da arte popular. "Toda a arte popular anda ligada ao trabalho. O trabalho é a maior epopeia que o povo tem traçado no mundo, só à espera de um poeta que lhe erga um cântico sublime, um canto de hossana e redenção. É a trabalhar que o povo cultiva as suas canções e a sua poesia, tão imitada e jamais atingida" (ibidem).

Traça depois o panorama músico-instrumental de Portugal (apenas Continental), percorrendo de Norte a Sul as Províncias na sua diversidade regional. Só com Ernesto Veiga de Oliveira (1962), em 1962, será possível encontrar uma síntese tão completa, decorrente de um conhecimento profundo das regiões.

No texto dactilografado que estou a citar (Redol, 1939b), há anotações do maior interesse para o que nos importa. Refiro-me aos exemplos musicais, realizados por executantes durante a conferência, que mostram como a ligação de Redol à música se baseava num conhecimento directo.

Para ilustrar os pregões:

- uma voz de mulher apregoa figos (os lampos, os moscatéis, os vindimos)

- uma voz de homem apregoa morangos (Nos cestinhos altos, de verga arroxeada, enfiando os braços no pau que leva ao ombro)

- Uma voz de mulher apregoa queijos (louça e roliça, nos seus trajes garridos, passa a saloia dos queijos)

E descreve como esses sons estão profundamente ligados à vida do povo:

É nos pregões das ruas; nas canções de berço com que as mãis martirizadas por um dia de trabalho, nos campos ou nas fábricas, embalam e adormecem seus filhinhos; é nas danças de roda que a petizada palreira brinca nas ruas e nos adros; nas serenatas, acompanhadas a guitarra, ou nos corais grandiosos dos alentejanos apaixonados, embevecendo no leito a cachopa dos seus sonhos; é no cantos litúrgicos, graves e dolentes; nos alegres folguedos das fogueiras e das romarias; é nas horas de ceifa, quando o sol aquebranta os corpos e a água não apaga o fogo que lá dentro irrompe; nas horas de desalento e nas horas de festança.

Às vezes para festejar uma esperança, outras, quasi sempre, para afogar um desengano.

Intervenções musicais na palestra: ${ }^{3}$

(Minho)

- um coro misto canta a caninha verde, ouvindo-se o repicar dos ferrinhos acompanhando a melodia

(Trás os Montes) 
- um coro de homens canta a rabatida ${ }^{4}$

(Beira Alta)

- um coro de mulheres canta a Narda

(Beira Baixa)

- duas concertinas tocam uma música beirã

(Estremadura) “... o fado, falsamente apelidado de canção nacional e que é uma reminiscência do lundum, música brasileira de origem africana"

- acompanhada por guitarra e viola uma voz canta o fado

(Ribatejo)

"Vivendo do Tejo que lhe corre nas veias, típico no campino, guardador de manadas de éguas e toiros, e no pescador, vindo da Beira Litoral, está o Ribatejo. Perto da charrua que a tralhoada arrasta, erguem-se as lanças dos mastros, espraiam-se os polígonos das salinas. Nos montes do Norte choram moinhos, encarrapitados em altares de vinhas e remendos de culturas. E o fandango aqui é rei, que a batê-lo ninguém é mais caprichoso do que o homem da Borda d'Água"

- duas concertinas tocam o fandango

"Se um harmonium canta no terreiro das poisadas ou nos cais, quando os ranchos esperam embarque para irem ao trabalho e as sezões, logo ali se arma a roda. E em verde-gaios e bailaricos não há gente mais decidida.”

- duas concertinas tocam um bailarico

(Alentejo)

- um coro de homens canta, a duas vozes, uma canção alentejana

(Algarve)

- concertinas tocam um corridinho.

Redol termina a palestra dizendo: 'É assim a música do povo. Conhecê-la é admirá-la, como se admira e ama o seu criador. Que eu não tenho que o amar senão como um homem do povo que se orgulha dos atributos da sua gente" (ibidem).

Alves Redol não teve à época a possibilidade de utilizar um gravador. Os seus "instrumentos" eram os cadernos de apontamentos e a máquina fotográfica (Figura 4). A música, manuscrita em partitura por quem o sabia. As duas partituras que acompanham o seu texto sobre o Fandango terão sido escritas talvez pela sua mulher, Maria dos Santos Mota ou por Manuela Câncio Reis, esposa de Soeiro Pereira Gomes, ambas com formação musical.

Situação bem diferente das condições proporcionadas a Armando Leça (1891-1977) que foi "uma espécie de 'etnomusicólogo oficial' do Estado Novo" (Sardo, 2009, p.425). Susana Sardo lembra-nos que no "estudo da música popular em Portugal as tecnologias de gravação de som só [vieram] a ser utilizadas pela primeira vez, e de uma forma exaustiva, por Kurt Schindler, entre 1928 e 1931 (Schindler, 1941) e, em 1939/40, por Armando Leça, o primeiro português a fazer uso da gravação sonora no terreno, num trabalho de dimensão nacional". 


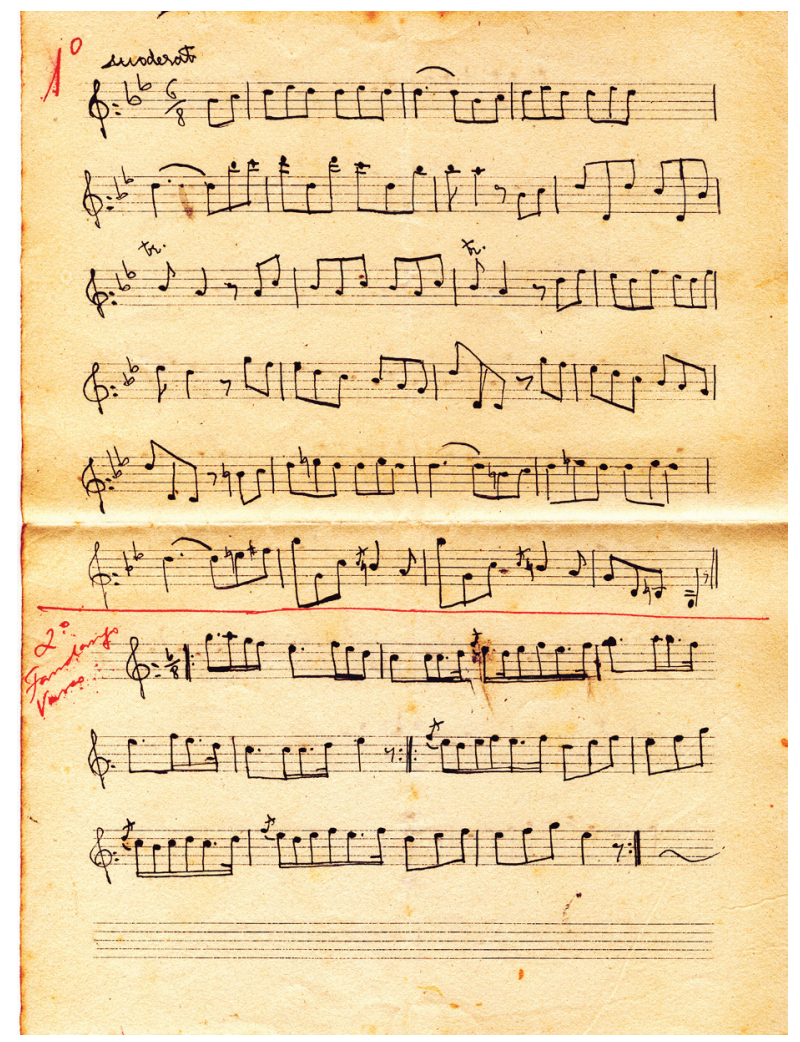

Figura 4

Vale a pena referir o custo deste levantamento (Pestana, 2012, p.196) tornado possível pela sua inclusão nas comemorações de 1940 do duplo centenário - Independência e Restauração assumido pelo Estado Novo e coordenadas por António Ferro:

- aquisição de equipamento de gravação: 2 aparelhos de gravação eléctrica Magnetophon, modelo K4, 20 bobines com fitas e nucleos metálicos, ao preço total e líquido de $62.673 \$ 00[\ldots]$

- verbas inscritas no orçamento das comemorações para a edição: despesas com material e prensagem para gravação dos trechos seleccionados de música popular portuguesa: 118.000\$; discos virgens: 230.000\$; prensagem de matrizes: 95.000\$; despesas não especificadas com pessoal e ajudas de custo, a suportar pela Comissão Executiva dos Centenários.

É evidente a forma como o acesso a estes recursos, considerados os mais adequados para o registo da música, apenas estavam à disposição de quem estava próximo do Poder e não punha em causa as opções de política cultural vigentes. ${ }^{5}$

Mas todo esse investimento poderia ter sido perdido. Os registos foram realizados (por uma equipa técnica dirigida por Armando Leça) mas a edição ficou esquecida, passado o entusiasmo das Comemorações.

José Alberto Sardinha (1992, p.345) diz-nos como, em 1983, foi possível encontrar esses suportes na antiga Emissora Nacional: 
Armando Leça foi convidado em 1939 para efectuar uma recolha nacional de cantares e danças populares, pela Comissão Executiva dos Centenários, que o Estado Novo nomeara para celebrar o oitavo centenário da Nacionalidade e o terceiro da Restauração. O objectivo era organizar uma compilação das mais características e genuínas músicas e canções populares existentes em todas as províncias do continente português [...].

No prazo de escassos meses, entre Novembro de 1939 e Abril de 1940, percorreu, gravando grupos de populares, as seguintes Províncias e regiões: $1^{\text {a }}$ fase, de 3/11/1939 a 18/11/1939,-Algarve, Baixo Alentejo e Alto Alentejo; $2^{\text {a }}$ fase, de 27/11/ 1939 a 22/12/1939 - Ribatejo, Beira Baixa, Beira Transmontana, Alto Douro e Beira Litoral; $3^{\text {a }}$ fase, de 26/2/40 a 18/4/40 - Beira Litoral, Beira Alta, Trás-os-Montes, Minho, Douro Litoral, Terras de Basto e novamente Beira Litoral. O registo de som, feito em fita magnética, esteve a cargo da então Emissora Nacional. [...] Em certa altura chegaram mesmo a dar-se como perdidas, por descaminho dos originais. [...]

Ora, em 1983, quando fomos convidados pelo Programa 2 da RDP a fazer um programa radiofónico que tomou o nome de "Cancioneiro popular", fizemos sentir ao realizador Bemardino Pontes a importância das gravações de Armando Leça e a necessidade de elas serem encontradas e difundidas para o grande público. Foi graças ao seu esforço e pertinácia que, após alguns meses de buscas nos arquivos da antiga Emissora Nacional, foi possível encontrar uma cópia dessas gravações.

Da lista de registos de Armando Leça, destacamos os que podem documentar a música no Ribatejo em 1940:

\section{MILAGRES, LEIRIA}

Margarida moleira - dança de roda, cantada em leixa-pren, ${ }^{6}$ por coro feminino monódico.

Linda machada - idem.

Palmas, palmas - idem.

Lavrador da Arada - romance religioso cantado por coro feminino.

S. João Alteres maior - romance religioso cantado por coro feminino.

Bailarico - gaita ou harmônica de boca, acompanhando solo da cantadeira, com resposta de coro feminino, a uma voz.

Ciranda - harmónio; cantadeira com resposta de coro feminino no refrão.

Verde gaio - harmónica de boca e coro feminino.

AZINHAGA, GOLEGÃ

Pombo arrulador - coro misto; dança de roda.

Já apanhámos a azeitona - coro misto.

Vamos ao vira - harmónio acompanhando coro misto,

Bailarico - idem.

Verde gaio - só harmónio.

Fandango - idem.

PEGO, ABRANTES

Nossa aldeia do Pego - acordeão acompanhando coro misto.

Chora a videira - idem. 
A obra de Armando Leça foi objecto de uma análise cuidada e isenta realizada por Maria do Rosário Pestana e pelo Museu da Música Portuguesa, em 2012, num estudo e exposição que permitem compreender o contributo do investigador e o seu pensamento, nem sempre coincidente com o ideário do Estado Novo. Foi no entanto um dos promotores principais da "reconstituição folclórica" e de iniciativas nacionais a partir da segunda metade da década de 1930: "Concurso do Cacho Dourado", "Grande Cortejo Folclórico" e "Aldeia mais portuguesa de Portugal". Defendeu também uma visão paralisante da música e da dança nos Ranchos Folclóricos que apenas permitia o que se considerava "antigo e autêntico". As Federações de Folclore, instituições poderosas ainda hoje, continuam esse ideário que condiciona negativamente os repertórios desses grupos.

A presença de músicos que participaram activamente em todas as iniciativas a que Redol esteve ligado é por demais evidente. No Grupo Neorrealista de Vila Franca, desde a sua formação em 1937, estava Emílio Diniz Lopes, ${ }^{7}$ compositor e professor no Conservatório Nacional. Carlos Tomé e Sebastião Gois aparecem ao lado de Redol na palestra "A música da Borda d'Água" de 25/10/1940. Arquimedes da Silva Santos é um melómano e músico amador que foi aluno de piano de Emílio Lopes. E Fernando Lopes-Graça que viria gradualmente a assumir a realização musical dos propósitos do programa dos criadores neorrealistas.

O ensaio de Manuel Denis Silva publicado no catálogo da Exposição Documental do Movimento Neorrealista Português em 2007 (Silva, 2007) refere Lopes-Graça em sintonia com os propósitos enunciados por João José Cochofel em 1943 (Cochofel, 1943a) na criação de uma nova música recusando o puro jogo técnico p.e. no "retorno a Bach de Stravinsky, privilegiando antes as novas vias abertas por Bartok, Prokofiev, Chostakvitch, Alois Haba, Manuel de Falla e, em Portugal, Lopes-Graça” .

Apresenta mesmo todo um programa (Cochofel, 1943b) de que destaco alguns itens:

1. A "assimilação de temas populares" não como "pretexto folclórico" mas como uma prospecção do que "há de mais profundo no sentimento musical do povo".

2. A criação de novos temas e de novos ritmos que traduzissem as novas realidades da vida contemporânea, "a trepidação das máquinas, trabalho das oficinas, a invasão dos campos pelos tratores e máquinas agrícolas" [...]

3. O desenvolvimento de género intimista como a música de câmara [...] onde se poderiam traduzir a "vida psíquica e os sentimentos mais íntimos", dando sempre preferência aos que "revelam o sentido obstrutivo da vida, cantando o carácter heróico e não a nostalgia, as emoções vigorosas e não o requinte subjectivo".

4. O desenvolvimento da música coral, "um excelente meio de interpretar o sentimento colectivo". 
Manuel Denis Silva realça neste "programa prospectivo" a "forma não hierárquica" como as diferentes possibilidades se encontravam dispostas. Além disso, confundiam-se no interior da enumeração critérios habitualmente separados, como o popular e o erudito, a música instrumental e a vocal, as expressões "pura" e as de "intervenção".

\section{A música da Borda d'Água}

Nas duas palestras referidas no início, $A$ arte do povo do Ribatejo, de 16/7/1938 (Alves Redol, 1939c) e O Fandango (Alves Redol, 1939a) de 18 de janeiro de 1939, Redol fala das práticas performativas dos povos do Ribatejo, com a desenvoltura e acertividade de quem conhece as pessoas, contextos, modos de vida, problemas e paixões, contradições e religiosidade manifesta. É patente a sua visão da mudança permanente e das marcas da modernidade que o século $\mathrm{XX}$ trouxe, ao mundo rural e às comunidades que o constituem. O Ribatejo de que nos fala resulta da confluência de culturas de várias regiões do país devido aos trabalhos sazonais, como a cultura do arroz, ou às condições oferecidas na bacia do Tejo aos pescadores do Norte (avieiros). Revela a capacidade que as comunidades têm de se afirmar, adaptando, recriando, inventando o que melhor as serve nos seus cantos, danças, representações, festividades e celebrações.

Redol fala da dança com especial desenvoltura. Em futuros projectos nem sempre levados a termo, como o guião de documentário $O$ Tejo: vida de um rio (Alves Redol, s. d.), reserva mesmo para si esse tema (e também a pesca) enquanto a música estaria a cargo de Lopes-Graça (Figura 5).

Traça uma longa história das danças peninsulares e revela uma extensa consulta de fontes documentais. As danças do Ribatejo seriam resultantes de inúmeros contributos em que destaca as saias e bailes de roda do Alentejo, que os camponeses ribatejanos rebaptizam: "calças" e "rabanasca". Os "viras", a "farrapeira" (dançada na Glória do Ribatejo), a "tirana" e o "real das canas" dos ovarinos, a "caninha verde", a "marmelada", dança mimada, graciosa e desenvolta que Redol diz nunca ter visto referenciada. E os "bailaricos", do saloios estremenhos, que se transfiguram em "fandangos". Fandango que Redol diz ter vindo de Espanha, da Andaluzia, para as províncias do Levante e para o País Basco.

Enumera muitas dessas danças, contextualizadas na sua obra literária. $\mathrm{O}$ "verde gaio" e o "vira" são descritos com detalhe que permite reconstituí-los. O "bailarico", a "tirana", e poderia continuar a citar o que Redol conheceu. Nos antípodas das perspectivas reducionistas e sufocantes do folclorismo bacoco reinante no Estado Novo.

Os instrumentos usados incluem quase todos os que conhecemos em Portugal. O harmónio, a concertina (também conhecida por "piano de cavalariça”), a gaita de beiços, as gaitas de foles, as violas e as guitarras, as flautas de cana. E podemos encontrar referências à castanhola de cana, ao cântaro com abano, grande "quarta" de barro, que se leva sob o braço esquerdo e sobre cuja boca se bate com um abano. 

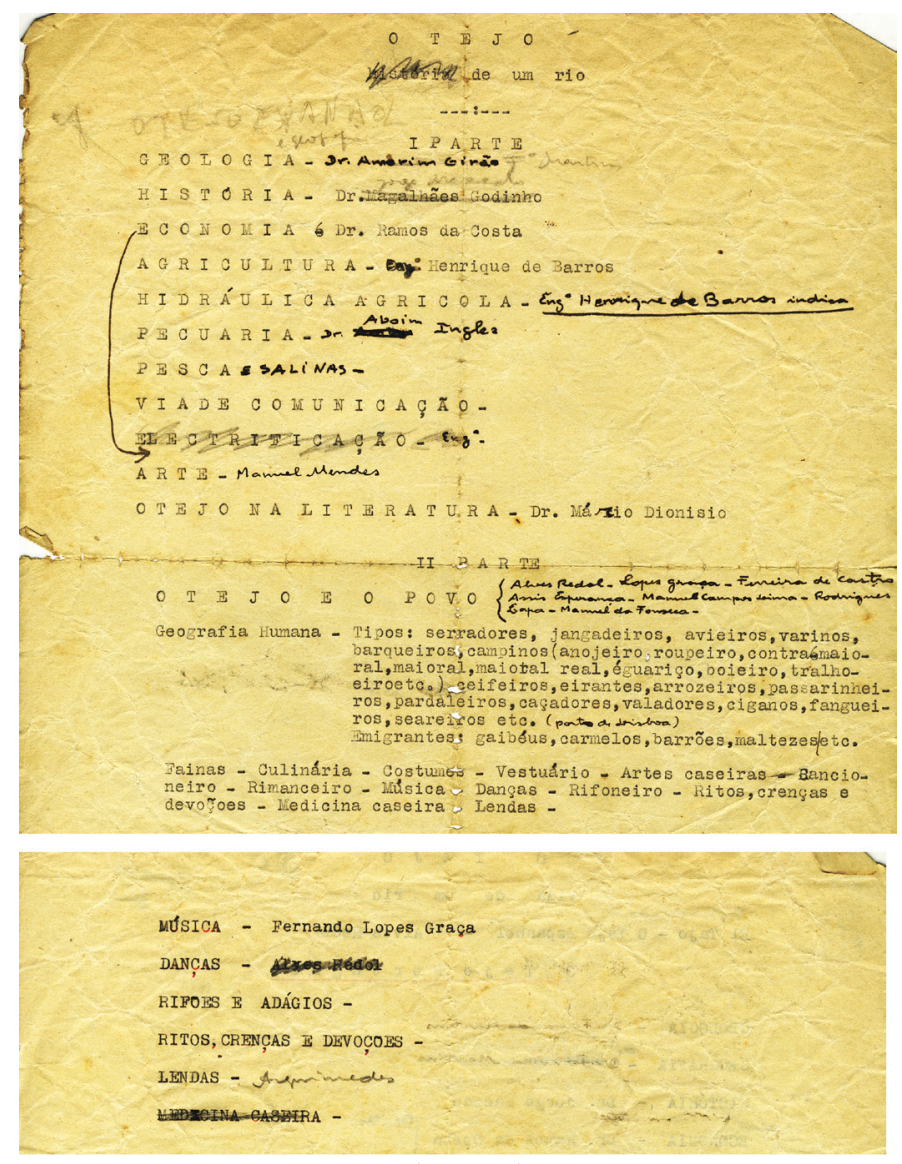

Figura 5

Não tivemos acesso às gravações de Armando Leça, em vias de publicação. Procurámos nas recolhas feitas por investigadores como Laura Boulton ${ }^{8}$ se haveria alguns registos do Ribatejo. A imprecisão da documentação que acompanha os fonogramas permite ainda assim seleccionar alguns que se podem considerar próximos das práticas performativas Ribatejanas.

Mas onde encontrámos uma maior similitude com o complexo cultural dos povos da Borda d'Água, foi numa edição recente da filmografia completa de Michel Giacometti no volume dedicado ao Ladrão do Sado (Giacometti, 2010), sobre a música e dança no Vale do Sado, realizado em 1982 com uma população constituída também por comunidades piscatórias oriundas do Ribatejo, na procura de melhores condições de subsistência e de imigrantes sazonais para as safras do arroz, tal como no Ribatejo.

As Tradições musicais da Estremadura de José Alberto Sardinha (2000), editado pela Tradisom em 2000 e o Cancioneiro d' Entre Mar e Serra da Alta Estremadura, de José Ribeiro e Sousa (2003), editado pela Câmara Municipal de Leiria em 2003 são fontes muito próximas dos repertórios ribatejanos.

Uma referência breve ao Cancioneiro do Ribatejo de Alves Redol (1950). O seu prefácio é de uma actualidade e visão que nos ajuda a discernir ainda hoje 
quais os processos e motivações da criação popular. Falta-lhe o complemento dos registos fonográficos e filmes que a escassez de meios e o boicote dos apoios públicos explicam. Temos as imagens registadas pela câmara fotográfica de Redol e a sua mestria em nos descrever e contar com palavras nos seus estudos, contos e romances. E o tratamento exaustivo, resultante de muitos anos de recolha no terreno do próprio Redol e de um grupo de colaboradores da poesia popular, dita e cantada no Ribatejo.

Redol e o movimento neorrealista apercebem-se desde a década de 1930 da importância da rádio e do cinema. Os projectos de guiões de filmes que não foi possível realizar mostram como dominavam a escrita para rádio e cinema.

Porque não, tomar, como ponto de partida, alguns dos seus guiões e dar-lhes, com os meios e conhecimento de que dispomos hoje, a finalização que merecem?

Lopes-Graça, que citamos no início, terá assumido um papel determinante na concretização dos propósitos enunciados no movimento neorrealista para a arte musical. Retomamos e completamos por isso a citação inicial, republicada por Alexandre Branco Weffort (2006, p.37) em 2006:

Há que restituir ao povo a sua música. Há que restituir-lha por dever e por necessidade: por dever humano e por necessidade estética. Por dever humano, porque a música é um bem comum, uma riqueza que por todos deve ser partilhada, uma eucaristia que todos têm o direito de comungar; e por necessidade estética, porque, desde sempre, e sobretudo nas épocas de crise, a música se foi retemperar nas fontes vivas da arte popular do perigo que corria de se esterilizar no afinamento extremo dos meios técnicos e especulativismo das questões teóricas, com prejuízo da verdade, da força e da humanidade da sua mensagem.

\section{Notas}

1 Escritor português, natural de Vila Franca de Xira, António Alves Redol nasceu a 29 de dezembro de 1911 e faleceu a 29 de novembro de 1969. Figura central do neorrealismo português, foi autor de uma vasta obra ficcional, que inclui o teatro e o conto. Alves Redol. In Infogédia [em linha]. Porto: Porto Editora, 2003-2013 [Consult. 31.8.2013]. Disponível em: <http://www.infopedia.pt/\$alves.redol>

2 César Cui (1835-1918). Compositor e crítico musical russo.

3 É possível que algumas dessas músicas tenham sido reproduzidas num aparelho de fita ou numa grafonola.

4 Cantiga bailada recolhida dos "pauliteiros" de Cércio (Rabatida).

5 Fernando Lopes-Graça apenas terá podido utilizar um gravador de fita em 1953 quando realiza uma prospecção folclórica na Beira Baixa. E só com Michel Giacometti será possível dar início em 1959 aos Arquivos Sonoros Portugueses.

6 Leixa-pren - processo pelo qual se retoma no início de uma copla o último verso da estrofe anterior, embora alternando as últimas palavras. 
7 Emílio Diniz Lopes fez parte do grupo "Mocidade Esperançosa” com Alves Redol nos anos 20 do século XX.

8 Laura Boulton (1899-1980). Etnomusicóloga americana (Estados Unidos). Gravou música popular e fado em Portugal em 1953. Os seus trabalhos estão depositados na Boulton Collections em Indiana, Columbia, Harvard University e na Library of Congress dos Estados Unidos.

\section{Referências}

ALVES REDOL, A. Fandango. Mensageiro do Ribatejo, a.10, n.452, 1939a.

. Música popular. Palestra proferida no segundo serão de arte, organizado pela secção cultural do Sport Lisboa e Vila Franca, na Sociedade União Musical, na noite de 29 de Março de 1939b.

. A arte do povo do Ribatejo. Conferência realizada a 10/7/1938 no Cinema, Teatro de Vila Franca de Xira. 1939c.

. Cancioneiro do Ribatejo, Vila Franca de Xira, Centro Bibliográfico, 1950.

. O Tejo: vida de um Rio [Registo vídeo]. s. 1.: s. n., s. d.

COCHOFEL, J. J. A música e o nosso tempo I. Seara Nova, n.832, 1943 a.

. A música e o nosso tempo II. Seara Nova, n.833, 1943 b.

GIACOMETTI, M. Michel Giacometti [Registo sonoro]: O ladrão do Sado, trans. Orlando Leite. s. 1.: Tradisom, 2010.

LOPES-GRAÇA, F. Sobre o conceito de música portuguesa. Seara Nova, n.740-742, 1941.

OLIVEIRA, E. V. Instrumentos musicais populares portugueses. Lisboa: F. C. Gulbenkian, 1962.

PESTANA, M. do R. Armando Leça e a música portuguesa. Lisboa: Edições Tinta da China, 2012.

SANTOS, D. (Org.) Alves Redol: Horizonte revelado. Vila Franca de Xira: Câmara Municipal de V. F. de Xira, Museu do Neorrealismo, Assírio \& Alvim, 2011.

SARDINHA, J. A. Armando Leça e o primeiro levantamento músico-popular realizado em Portugal. Revista da Faculdade de Ciências Sociais e Humanas, Lisboa, Universidade Nova, p.345-376, 1992.

. Tradições musicais da Estremadura. Vila Verde: Tradisom, 2000.

SARDO, S. Música Popular e diferenças regionais. In: Multiculturalidade: Raízes e Estruturas. Lisboa: Universidade Católica Portuguesa, 2009. v.I: cap.11 (Col. Portugal Intercultural).

SCHINDLER, K. Folk song and poetry from Spain and Portugal. New York: Hispanic Institute, 1941.

SILVA, M. D. A Lira que brada: a música como problema do neorrealismo português. In: SANTOS, D.; REDOL, A. (Ed.) Batalha pelo conteúdo: Movimento Neorrealista Português: Exposição Documental. Vila Franca de Xira: Câmara Municipal de Vila Franca de Xira, Museu do Neorrealismo, 2007. p.274-91. 
SOUSA, J. R. de. Cancioneiro d'Entre Mar e Serra da Alta Estremadura. Leiria: Câmara Municipal de Leiria, 2003.

WEFFORT, A. B. A canção popular portuguesa em Fernando Lopes-Graça. Lisboa: Editorial Caminho, 2006.

RESUMO - António Alves Redol, escritor português natural de Vila Franca de Xira, nasceu a 29 de dezembro de 1911 e faleceu a 29 de novembro de 1969. Figura central do Neorrealismo português, foi autor de uma vasta obra ficcional, que inclui o teatro e o conto. Na noite de 25 de outubro de 1940, no Sport Lisboa e Vila Franca, realizou uma palestra sobre a "Música da Borda d'Água" de que não há registo conhecido. Tentamos refazer essa palestra, ou pelo menos as linhas orientadoras do seu discurso, recorrendo a textos de Redol, alguns inéditos, dos anos de 1938 e 1939, que nos foi possível consultar e digitalizar nos acervos do seu filho, António Mota Redol, em outubro de 2012. Na obra de Redol, as referências à música e dança são estruturantes das situações que descreve. Sem entrar em detalhes técnicos que talvez ignorasse, o que nos diz é revelador de como o movimento neorrealista, que tem em Fernando Lopes-Graça um solitário mentor, não descurou os repertórios e cancioneiros populares, contrapondo-os às práticas e gostos musicais das classes dominantes.

PALAVRAS-CHAVE: Alves Redol, Neorrealismo, Música popular portuguesa, Ribatejo.

ABSTRACT - António Alves Redol, Portuguese writer from the town of Vila Franca de Xira, was born on 29th December 1911 and died on 29th November 1969. A central figure in the Portuguese Neorealist movement (Neorealism) he was the author of a vast fictional body of work which includes theatre and short stories. On the evening of 25th October 1940, at the headquarters of the Sport Lisboa e Vila Franca football club, he delivered a lecture on "Borda d'Água Música" of which there is no known record. We have tried to reconstruct this lecture or at least its speech guidelines resorting to Redol's texts, some unpublished, from 1938 and 1939, which we were able to see and scan in his son's collection, António Mota Redol, in October 2012. In Redol's work, the references to music and dance are structural to the situations he describes. Without going into technical details, something which he might have been ignorant of, what he conveys reveals how the Neorealist movement, that has a lonely mentor in Fernando Lopes-Graça, did not neglect the repertoires and popular cancioneiros (songbooks), setting them against the practices and musical taste of the dominant classes.

KErWORDS: Alves Redol, Neorealism, Portuguese popular music, Ribatejo.

Domingos Morais é membro do Instituto de Estudos de Literatura Tradicional da Faculdade de Ciências Sociais e Humanas da Universidade Nova de Lisboa (IELT) e do Movimento Português de Intervenção Artística e Educação pela Arte (MPIAEA). @ - domingosmorais@gmail.com

Recebido em 30.9.2013 e aceito em 15.10.2013.

I Instituto de Estudos de Literatura e Tradição, Faculdade de Ciências Sociais e Humanas, Universidade Nova de Lisboa, Lisboa, Portugal. 